\title{
Development of an isothermal amplification-based assay for the rapid visual detection of Salmonella bacteria
}

\author{
Hai-bin Liu, ${ }^{*}$ Yu-Xuan Zang, ${ }^{*}$ Xin-jun Du, ${ }^{*}$ Ping Li, ${ }^{,}$and Shuo Wang ${ }^{*}{ }^{1}$ \\ *Key Laboratory of Food Nutrition and Safety, Ministry of Education, Tianjin University of Science and Technology, Tianjin 300457, China \\ †Beijing Advanced Innovation Center for Food Nutrition and Human Health, Beijing Technology \& Business University, Beijing 100048, China
}

\begin{abstract}
The efficient and timely detection of pathogens is a major concern worldwide. The aim of this study was to establish a rapid detection method for Salmonella bacteria in food samples to facilitate timely treatment. Widely used detection methods currently include culture-based methods and PCR-based methods. The former are time consuming, requiring 2 to $3 \mathrm{~d}$, whereas the latter have higher accuracy but are typically complicated, requiring expertise and expensive instruments. In this study, a sensitive and rapid approach for the visual and point-of-use detection of Salmonella bacteria based on recombinase polymerase amplification (RPA) and a lateral-flow (LF) nucleic acid strip was established. We designed a pair of primers according to the invA gene of Salmonella bacteria: one was modified with digoxin, and the other was modified with biotin. In the presence of the biotin- and digoxin-modified primers and target DNA, the RPA produced a substantial amount of duplex DNA attached to biotin and digoxin. The products were detected using LF strips through immunoreaction: anti-digoxin antibodies on the gold nanoparticles, digoxin on the duplex, streptavidin on the LF test line, and biotin on the duplex. The developed RPA-LF assay allowed detection of Salmonella genomic DNA in less than 20 min with simple water bath equipment or portable thermal equipment. In addition, the RPA-LF assay was highly sensitive, with a detection limit as low as $20 \mathrm{fg}$ of target DNA or $1.05 \times 10^{1}$ cfu of bacteria in pure culture, and highly specific, exhibiting no cross-reaction with Staphylococcus aureus, Escherichia coli, Listeria monocytogenes, Shigella, Enterobacter aerogenes, or Campylobacter jejuni. Importantly, Salmonella could be detected in milk and chicken breast at concentrations as low as $1.05 \times 10^{0} \mathrm{cfu} / \mathrm{mL}$ or $1.05 \times$
\end{abstract}

Received January 6, 2017

Accepted May 24, 2017.

${ }^{1}$ Corresponding author: s.wang@tust.edu.cn
$10^{0} \mathrm{cfu} / \mathrm{g}$ after enrichment for $2 \mathrm{~h}$ and in eggs at $1.05 \times$ $10^{0} \mathrm{cfu} / \mathrm{g}$ after enrichment for $4 \mathrm{~h}$. Furthermore, RPA was more sensitive than PCR, which requires a thermal cycling device. In summary, this study describes a sensitive, simple, and point-of-use detection method for Salmonella bacteria.

Key words: Salmonella, recombinase polymerase amplification, lateral-flow strip, nucleic acid test

\section{INTRODUCTION}

Organizations and consumers are paying increasing attention to food safety due to the frequent food safety incidents occurring in many countries. The Centers for Disease Control and Prevention (2014) estimates that disease caused by contamination with foodborne pathogens affects 48 million people and results in 128,000 hospitalizations and 3,000 deaths every year in the United States. Salmonella is considered an important risk to poultry and consumer health worldwide (Kutay et al., 2016) and is responsible for numerous foodborne illnesses around the world (Millan-Sango et al., 2016).

The standard culture-based methods for Salmonella detection are time consuming and labor intensive, requiring $3 \mathrm{~d}$ to obtain a presumptive positive or negative result and another 2 to $4 \mathrm{~d}$ to identify a positive result (Khueankhancharoen et al., 2016). Consequently, for food samples, the applications of conventional methods are limited. Polymerase chain reaction has been widely employed for the rapid detection of Salmonella. This technique requires expensive thermal cycling instruments and professional operators, which limit its application in point-of-use detection and resource-limited settings.

To enable point-of-use detection, new isothermal amplification technologies are being developed that are suitable for use in settings where infrastructure, expensive instruments, and technical expertise are not available (Gill and Ghaemi, 2008; Kim and Easley, 2011). Isothermal amplification involves the amplification of nucleic acids at a constant temperature. A variety of mechanisms have been developed, such as nucleic acid 
Table 1. Primers of basic recombinase polymerase amplification (RPA) and lateral-flow RPA assay used in this study

\begin{tabular}{ll}
\hline Assay & Primers $^{1}$ \\
\hline Basic RPA reaction & F: $5^{\prime}$-CTACAAGCATGAAATGGCAGAACAGCGTCG-3' \\
& R: 5'-CAACCAGATAGGTAGGTAATGGAATGACGA-3' \\
Lateral flow RPA reaction & F: 5'-digoxinCTACAAGCATGAAATGGCAGAACAGCGTCG-3' \\
& R: 5'-biotin-CAACCAGATAGGTAGGTAATGGAATGACGA-3' \\
\hline${ }^{1} \mathrm{~F}=$ forward; $\mathrm{R}=$ reverse &
\end{tabular}

${ }^{1} \mathrm{~F}=$ forward; $\mathrm{R}=$ reverse

sequence-based amplification (Liu et al., 2016), loopmediated isothermal amplification (Chen et al., 2016), helicase-dependent amplification (Chen et al., 2015), rolling circle amplification ( $\mathrm{Li}$ et al., 2016), recombinase polymerase amplification (RPA; Chao et al., 2015), and strand displacement amplification (Hellyer and Nadeau, 2004). Compared with these technologies, RPA has several advantages: RPA is faster $(<30$ $\min )$ and operates at a lower temperature $\left(37-42^{\circ} \mathrm{C}\right)$. In the RPA method, a recombinase complex is used to introduce primers to specific DNA sites. These primers are elongated by strand-displacing DNA polymerase, and the intermediates are stabilized by single-stranded DNA-binding proteins (Krõlov et al., 2014). For the visual detection of RPA production, compact instruments that are small and lightweight can be used. For point-of-use detection in a resource-limited setting, RPA in combination with a lateral-flow ( $\mathbf{L F}$ ) strip is a desirable option. The LF strips are simple devices that can be used to detect the target analyte in samples. The advantages of LF over other detection methods include its rapidity, low cost, ease of use, and longterm stability (Dzantiev et al., 2014). Colloidal gold is a commonly used label in LF detection. The mobile phase is driven by capillary action, which rehydrates the antibody-conjugated colloidal gold. When it is passed through the test zone, the target antigen is captured by the antibody-conjugated nanoparticles and accumulates, thereby allowing visual detection by the unaided eye (Hwang et al., 2016). This LF-based detection method does not require an electronic device to generate visual inspection results.

In the present study, we used the RPA reaction to amplify the Salmonella invA gene followed by LF to detect the result. The accumulation of gold nanoparticles (AuNP) produced a characteristic band on the test line, enabling the visual detection of Salmonella bacteria. After determining of the sensitivity and specificity of the assay, it was applied to test selected food samples. We compared the sensitivity of RPA-LF with that of PCR-LF. Based on our results, we conclude that RPA-LF is rapid, simple, and suitable for pointof-use detection.

\section{MATERIALS AND METHODS}

\section{Reagents and Instrumentation}

The RPA basic amplification kits were obtained from TwistDx Ltd. (Babraham, UK). All primers (Table 1) were obtained from Genewiz (Suzhou, China) and were suspended in water at a concentration of $10 \mu \mathrm{M}$. The DNA extraction kit was purchased from Tiangen (Beijing, China). Mouse anti-digoxin monoclonal antibody was purchased from Abcam (Cambridge, UK). Gold chloride trihydrate, trisodium citrate dihydrate, streptavidin, PBS (0.01 M), Tween 20, polyethylene glycol 20,000, BSA, and agarose were obtained from Sigma-Aldrich (St. Louis, MO). The plastic backing, sample pad, absorption pad, and nitrocellulose (NC) membrane were acquired from Millipore (Billerica, MA). Water was purified with a Milli-Q system (Millipore, Madrid, Spain). All solvents and other chemicals were analytical reagent grade.

\section{Bacterial Strains}

A total of 5 Salmonella strains and 6 other bacterial strains were used to determine the specificity of RPA (Table 2). These strains were stored in the Key Laboratory of Food Nutrition and Safety of the Ministry of Education, Tianjin University of Science and Technology (Tianjin, China). Stock cultures were stored at $-80^{\circ} \mathrm{C}$ in $0.8 \mathrm{~mL}$ of Luria-Bertani broth (Beijing Land Bridge Technology Co., Ltd., Beijing, China) and 0.2 $\mathrm{mL}$ of $80 \%$ glycerol. The DNA templates were extracted with the TIANamp Bacteria DNA kit (Tiangen).

\section{Primer Design and Screening}

Primers specific to the Salmonella invA gene (Abouzeed et al., 2000) were designed based on guidelines provided by TwistDx (Babraham, UK). A variety of forward and reverse primer candidates were chosen, and the amplification effects were observed. The set of primers that produced the brightest bands were modified with end-tags to make them compatible with LF detection. The primers are summarized in Table 1. 
Table 2. Bacterial strains used in our study

\begin{tabular}{ll}
\hline Species & Source \\
\hline Salmonella cholerae & CICC21494 \\
Salmonella enteritidis & CICC10867 \\
Salmonella paratyphi & CICC21501 \\
Salmonella enterica ssp. enterica & ATCC13076 \\
Salmonella typhi & CICC10982 \\
Escherichia coli & CICC10305 \\
Listeria monocytogenes & CICC21633 \\
Shigella & ATCC21535 \\
Enterobacter aerogenes & CICC10293 \\
Staphylococcus aureus & ATCC 25923 \\
Campylobacter jejuni & ATCC33560 \\
\hline
\end{tabular}

\section{RPA Reaction}

The RPA reaction was performed according to the manufacturer's recommended protocols (Cordray and Richards-Kortum, 2015). A variety of reaction temperatures and incubation times were tested to determine the optimal reaction conditions. For each reaction, 29.5 $\mu \mathrm{L}$ of rehydration buffer, $10.7 \mu \mathrm{L}$ of sterile water, 2.4 $\mu \mathrm{L}$ of forward and reverse primers $(10 \mu M)$, and $2.5 \mu \mathrm{L}$ of template were mixed. One enzyme pellet from the kit was added to each reaction; then, $2.5 \mu \mathrm{L}$ of magnesium acetate solution was added to the tube to start the reaction. The tubes were then briefly centrifuged and vortexed to thoroughly mix the samples. Subsequently, the tubes were incubated in a water bath at $36,37,38$, 39,40 , or $41^{\circ} \mathrm{C}$ (Lutz et al., 2010) for $2.5,5,10,15,20$, or $25 \mathrm{~min}$. After the RPA reaction, the products were heated at $82^{\circ} \mathrm{C}$ [slightly below the product melting temperature $(\mathbf{T m})$ ] for $5 \mathrm{~min}$ to denature the primer dimer. The products were analyzed by both gel electrophoresis and LF strip. For LF strip detection, $90 \mu \mathrm{L}$ of PBS was mixed with $10 \mu \mathrm{L}$ of RPA reaction product. Then, the mixture was transferred to the test strip, and the band was visualized within 5 min. For agarose gel electrophoresis detection, $5 \mu \mathrm{L}$ of RPA reaction product was transferred to $2 \%$ agarose gel and visualized by staining with ethidium bromide.

\section{Synthesis of Antibody-Conjugated AuNP}

Gold nanoparticles (nanospheres) with diameters of $15 \pm 3 \mathrm{~nm}$ were prepared according to previously reported methods (Hwang et al., 2016) and characterized by field emission electron microscopy (JEM-2010 FEF, JEOL, Tokyo, Japan) and UV/visible absorption spectroscopy (Supplemental Figure S1; https://doi. org/10.3168/jds.2017-12566). The anti-digoxin antibody was conjugated to functionalized AuNP according to a previously described method (Zhao et al., 2004). Under gentle stirring, $12 \mu \mathrm{L}$ of $1-\mathrm{mg} / \mathrm{mL}$ mouse antidigoxin monoclonal antibody was added to $1 \mathrm{~mL}$ of colloidal gold solution ( $\mathrm{pH}$ 8.5). After incubation for $1 \mathrm{~h}$ at $4^{\circ} \mathrm{C}, 20 \mu \mathrm{L}$ of $20 \%$ (wt/vol) BSA and $10 \mu \mathrm{L}$ of $20 \%$ polyethylene glycol 20,000 were added to the solution, which was then incubated for another $15 \mathrm{~min}$ at $4^{\circ} \mathrm{C}$. Subsequently, the mixture was centrifuged at $300 \mathrm{~g} / \mathrm{min}$ for $15 \mathrm{~min}$ at $4^{\circ} \mathrm{C}$, and the supernatant was transferred to a new microcentrifuge tube. Next, the new mixture was centrifuged again at $8,600 \mathrm{~g} / \mathrm{min}$ for $30 \mathrm{~min}$. The pellet was resuspended in $250 \mu \mathrm{L}$ of buffer ( $5 \%$ BSA, $0.025 \%$ Tween 20 , and $1 \%$ sodium azide).

\section{Assembly of the Paper-Based LF}

The principle of the LF strip is illustrated in Figure 1. The LF strips consisted of plastic backing, an NC membrane, a conjugation pad, a sample pad, and an absorption pad. The conjugation and sample pads were both made from glass fibers. The conjugate pad was saturated with antibody-conjugated AuNP and dried at room temperature. Prior to assembly, a goat antimouse antibody $(1 \mathrm{ng} / \mathrm{cm})$ and streptavidin $(0.7 \mathrm{ng} /$ $\mathrm{cm}$ ) were sprayed onto the $\mathrm{NC}$ membrane to produce the control and test lines, respectively. Then, the $\mathrm{NC}$ membrane was dried overnight in an oven at $37^{\circ} \mathrm{C}$. To assemble the test strip, the NC membrane was placed in the center of the plastic backing and overlapped with the absorption pad and sample pad on each side. The conjugate pad containing anti-digoxin antibody that was labeled with AuNP was placed between the sample pad and the NC membrane. The assembled card was cut into 3.7-mm-wide strips using a programmable cutter (Zeta Corporation, Gunpo, South Korea) and stored in desiccator at room temperature.

\section{Sensitivity and Specificity of the RPA-LF Assay}

The sensitivity and specificity of the RPA-LF assay were determined at the optimal reaction time and temperature. The DNA from an overnight culture of Salmonella was extracted using the TIANamp Bacteria DNA kit (Tiangen). The concentration of total isolated DNA was determined using a Nanodrop ND-1000 spectrophotometer (Thermo Fisher Scientific, Waltham, MA). The RPA assay was performed in duplicate using $20 \mathrm{ng}$ to $20 \mathrm{fg}$ of DNA as the template. The sensitivity of the RPA assay was determined using 10 -fold serial dilutions of the Salmonella culture. The DNA templates were prepared from the different concentrations of $\mathrm{Sal}$ monella cultures by heating the bacteria at $95^{\circ} \mathrm{C}$ for 10 min (Yang et al., 2016). The specificity of the RPA method was evaluated by cross-reactivity analysis using 5 Salmonella and 6 non-Salmonella species, which are listed in Table 2. Each assay was repeated 3 times. The 
detection limit was defined as the lowest concentration to test positive in all 3 repeat assays.

\section{Preparation of Salmonella-Spiked Samples and Simulated Sample Detection}

Salmonella was cultured in $9 \mathrm{~mL}$ of Luria-Bertani broth at $37^{\circ} \mathrm{C}$ for $24 \mathrm{~h}$, harvested by centrifugation at $4,000 \times g$ for $20 \mathrm{~min}$ at $4^{\circ} \mathrm{C}$, and washed 3 times with PBS (0.01 $M$ phosphate, $0.137 M \mathrm{NaCl}, \mathrm{pH}$ 7.3). The final pellet was then added to milk, chicken breast, or egg using 10-fold serial dilutions to achieve different concentrations $(\mathrm{cfu} / \mathrm{g}$ or $\mathrm{cfu} / \mathrm{mL}): 1.05 \times 10^{0}, 1.05 \times$ $10^{1}$, and $1.05 \times 10^{2}$. The milk, chicken breast, and egg, which were verified to be free of Salmonella according to the National Standard GB/47894-2010 (People's Republic of China, 2010), were purchased from a local supermarket. Inoculated samples $(25 \mathrm{~g}$ or $25 \mathrm{~mL})$ were added to the Luria Bertani enrichment broth (Beijing Land Bridge Technology Co., Ltd., Beijing, China) in a 1:10 ratio to obtain the first dilution. To assess the detection limits at different enrichment times, which were aimed at increasing the bacterial concentrations to detectable levels, the samples were incubated at $37^{\circ} \mathrm{C}$ for $0,1,2,3$, or $4 \mathrm{~h}$. Then, 1 -mL aliquots were collected at each time point and boiled for $10 \mathrm{~min}$ to release the DNA. The obtained liquid was used as the template for the subsequent RPA assay. Each food sample was tested twice, and each assay was repeated 3 times.

\section{RESULTS}

\section{Operating Principle of the RPA-LF}

The operating principle of the RPA-LF assay is based on sandwich-type reactions (Figure 1). The RPA was used to generate numerous biotin- and digoxin-labeled duplex DNA. The product solution was diluted 10 times with PBS ( $\mathrm{pH} 8.0$ ) and pipetted onto the sample pad. This solution, driven by capillary action, migrated through the conjugation pad and rehydrated the antidigoxin antibody-conjugated AuNP. The digoxin on the duplex DNA reacted with the anti-digoxin on the surface of the AuNP to form a biotin-duplex DNA-di-

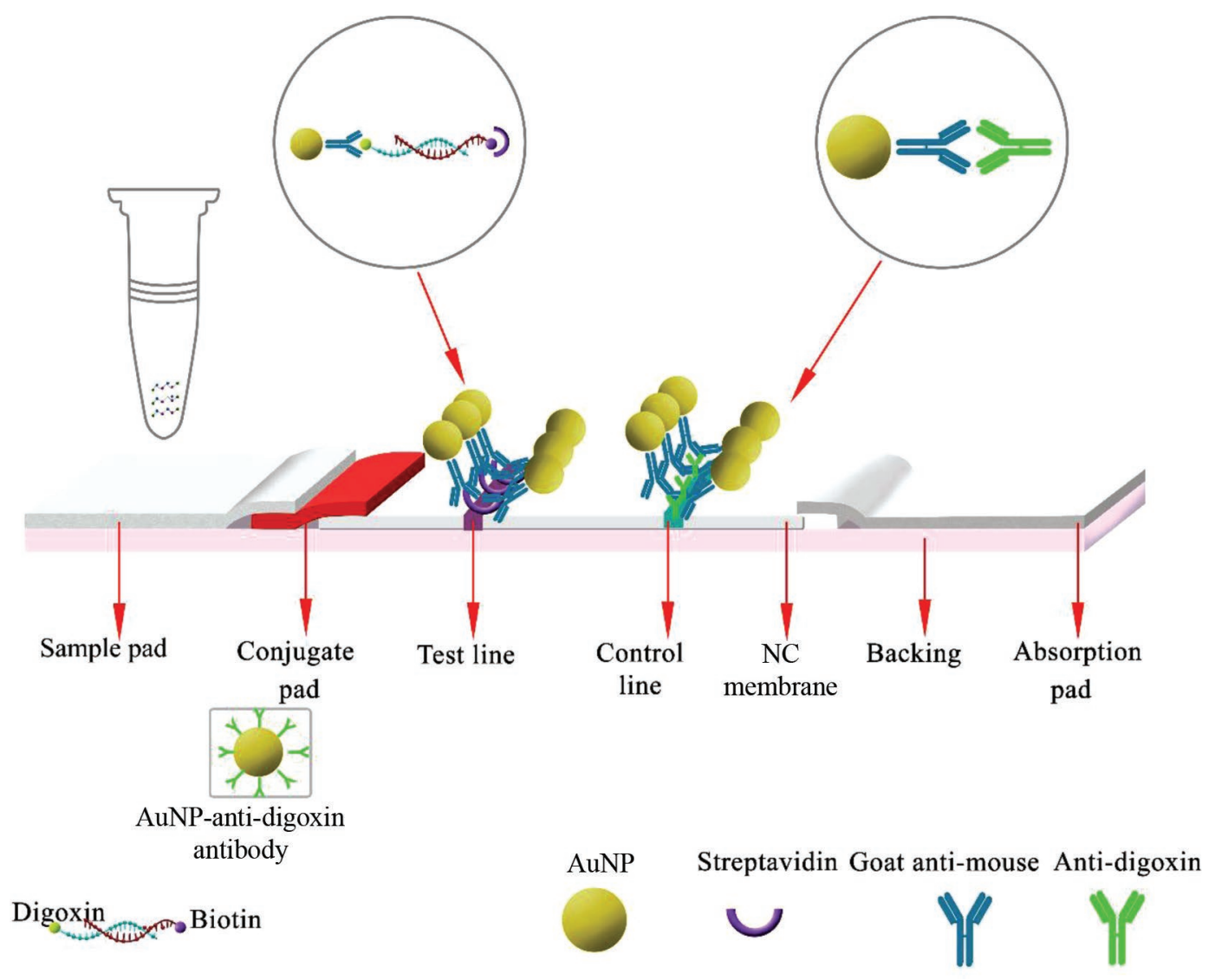

Figure 1. Schematic diagram of the recombinase polymerase amplification (RPA) lateral-flow (LF) nucleic acid biosensor for the detection of double-labeled (digoxin/biotin) invA gene. $\mathrm{NC}=$ nitrocellulose; AuNP = gold nanoparticles. Color version available online. 
goxin-anti-digoxin-AuNP complex, which continued to migrate along the strip. The complex was captured by streptavidin immobilized on the test line, which led to an increase in the number of AuNP complexes and the development of a visual band on the test line. Excess antibody-conjugated AuNP continued to migrate and were captured by the secondary antibody immobilized on the control line. Finally, in the presence of the target, 2 visual bands appeared (positive), whereas for negative samples, only one visual band was observed on the control line (negative). The visual band on the control line indicates that the LF strip functioned properly. To measure the sensitivity of the Salmonella RPA-LF assay, the detection limit was defined as the minimum target concentration that produced a visual band at the test line that was significantly different from the test line on the negative control strip. The LF strips were stable for at least 6 mo at room temperature. As shown in Supplemental Figure S2 (https://doi.org/10.3168/ jds.2017-12566), the brightness of the bands did not significantly differ between newly (LF1) and previously (LF2) prepared LF strips. To the best of our knowledge, this is the first RPA-LF assay developed to detect Salmonella bacteria.

\section{Performance of RPA}

The RPA reaction was performed according to the Quick Guide provided by the manufacturer. All reactions produced a visual band at $188 \mathrm{bp}$ after gel electrophoresis. The brightness of the band was directly proportional to the amount of template added to the RPA reaction (Figure 2B, 2D).
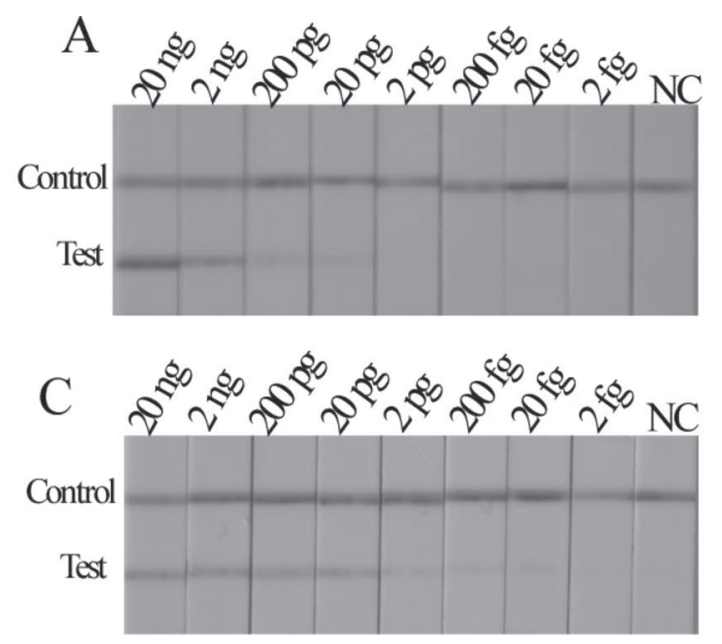

\section{Optimization of the RPA-LF Conditions}

To determine the optimal temperature for the RPA reaction, the RPA assay was tested at temperatures ranging from 36 to $41^{\circ} \mathrm{C}$. First, we assessed this range of temperatures using an incubation time of $10 \mathrm{~min}$ and analyzed the amplification products using LF strips. As shown in Figure 3A, weak test lines were obtained at 36,37 , and $38^{\circ} \mathrm{C}$, and no differences in amplification were detected among the temperatures of 39,40 , and $41^{\circ} \mathrm{C}$. Consequently, $39^{\circ} \mathrm{C}$ was selected arbitrarily as the reaction temperature for subsequent experiments. Next, we tested the effect of incubation time on amplification efficiency. We performed the RPA assay at $39^{\circ} \mathrm{C}$ and incubated for $2.5,5,10,15,20$, or $25 \mathrm{~min}$. As shown in Figure 3B, as the amplification time increased from 2.5 to $10 \mathrm{~min}$, the brightness of the strip increased. No differences in amplification were observed between the amplification times of 10 and $15 \mathrm{~min}$. When the amplification time was 20 or $25 \mathrm{~min}$, the band was brighter, but the reaction time was longer, and false-positive results were more likely to occur due to unexpected amplification or primer-dependent artifacts (Piepenburg et al., 2006). Thus, amplification times of 5 and 10 min were selected for the Salmonella RPA-LF assay in this study.

\section{Detection Limit of the RPA-LF Assay}

The Salmonella RPA assay was performed at $39^{\circ} \mathrm{C}$ with incubation times of 5 and $10 \mathrm{~min}$. Ten-fold serial dilutions of template DNA were prepared, corresponding to $20 \mathrm{ng}$ to $20 \mathrm{fg}$ of DNA. The products were ana-

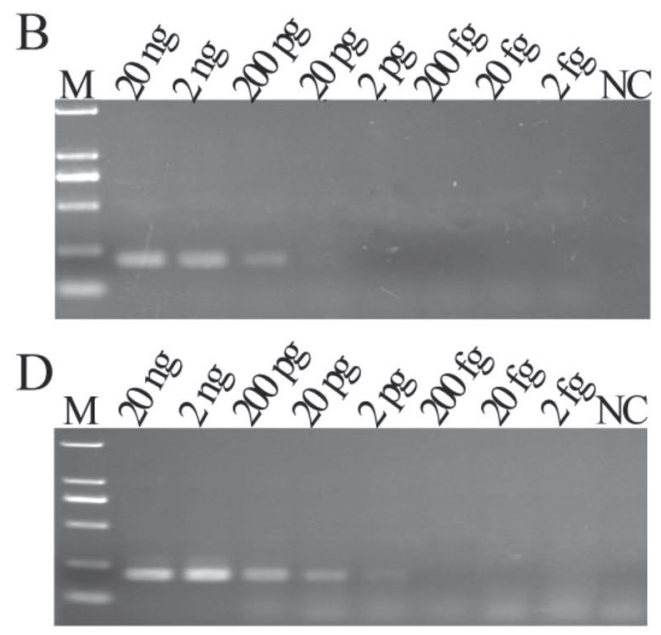

Figure 2. (A) Lateral-flow (LF) strips showing the detection limit of recombinase polymerase amplification (RPA) with an RPA incubation time of 5 min. (B) Agarose gel image of RPA amplicons with an RPA incubation time of 5 min. (C) Lateral flow strips showing the detection limit of RPA with an RPA incubation time of 10 min. (D) Agarose gel image of RPA amplicons with an RPA incubation time of 10 min. NC $=$ negative control; $\mathrm{M}=\mathrm{D} 2000 \mathrm{DNA}$ ladder used as size marker. 

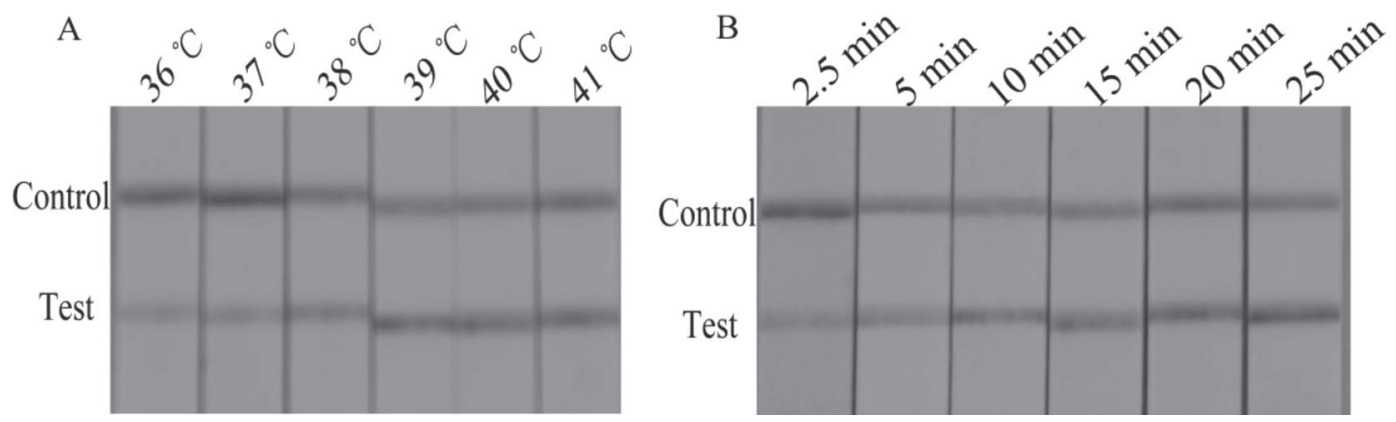

Figure 3. Optimization of the recombinase polymerase amplification (RPA) reaction temperature (A) and incubation time (B) using target DNA.

lyzed using LF strips and agarose gel electrophoresis. The 5-min RPA incubation had detection limits of 20 and 200 pg by LF and agarose gel electrophoresis, respectively (Figure 2A, 2B). In contrast, the 10-min RPA incubation resulted in detection limits as low as $20 \mathrm{fg}$ and $2 \mathrm{pg}$ by LF and agarose gel electrophoresis, respectively (Figure 2C, 2D). Furthermore, the color of the visual band on the test line observed using $20 \mathrm{fg}$ of target DNA of Salmonella differed significantly from that observed for the negative control without Salmonella. Therefore, $20 \mathrm{fg}$ of target DNA was considered the visual detection limit of the RPA-LF assay.

The RPA-LF assay and PCR-LF assay were applied to pure cultures with different concentrations of Salmonella ranging from $1.05 \times 10^{0}$ to $1.05 \times 10^{8} \mathrm{cfu} / \mathrm{mL}$. As shown in Figure 4, $1.05 \times 10^{1} \mathrm{cfu} / \mathrm{mL}$ of Salmonella could be detected using the RPA-LF assay, whereas $1.05 \times 10^{5} \mathrm{cfu} / \mathrm{mL}$ of Salmonella was required for detection using the PCR-LF assay. Therefore, the RPA-LF assay had a lower detection limit than did the PCR-LF assay.

\section{Specificity of the Protocol}

To assess the specificity of the RPA-LF assay under the optimal conditions determined above, 5 Salmonella and 6 non-Salmonella strains that frequently contami- nate food were amplified by RPA and observed using LF strips. As shown in Figure 5, the 5 Salmonella strains produced a visual band at the test line, whereas the 6 non-Salmonella strains only generated a visual band at the control line. Therefore, no cross-reactions were observed in the Salmonella strains examined, and the RPA-LF assay was specific for the detection of Salmonella bacteria.

\section{Application to Food Samples}

The developed RPA-LF assay was evaluated with milk, chicken breast, and egg samples spiked with Salmonella at concentrations ranging from $1.05 \times 10^{0}$ to $1.05 \times 10^{2} \mathrm{cfu} / \mathrm{mL}$ or $\mathrm{cfu} / \mathrm{g}$. The spiked samples were subsequently incubated for 0 to $4 \mathrm{~h}$ to determine the optimal enrichment time for different concentrations of Salmonella. In milk and chicken breast, positive results were obtained for the samples containing $1.05 \times 10^{2}$ $\mathrm{cfu} / \mathrm{mL}$ or $1.05 \times 10^{2} \mathrm{cfu} / \mathrm{g}$ of Salmonella immediately after the sample was added to the enrichment culture (Figure 6 ). The RPA-LF assay could detect $1.05 \times 10^{1}$ $\mathrm{cfu} / \mathrm{mL}, 1.05 \times 10^{1} \mathrm{cfu} / \mathrm{g}$, and $1.05 \times 10^{2} \mathrm{cfu} / \mathrm{g}$ in milk, chicken breast, and egg, respectively, after at least 1 $\mathrm{h}$ of enrichment at $37^{\circ} \mathrm{C}$. The RPA-LF assay detected $1.05 \times 10^{0} \mathrm{cfu} / \mathrm{mL}, 1.05 \times 10^{0} \mathrm{cfu} / \mathrm{g}$, and $1.05 \times 10^{1}$ $\mathrm{cfu} / \mathrm{g}$ of Salmonella after $2 \mathrm{~h}$ of enrichment in milk,
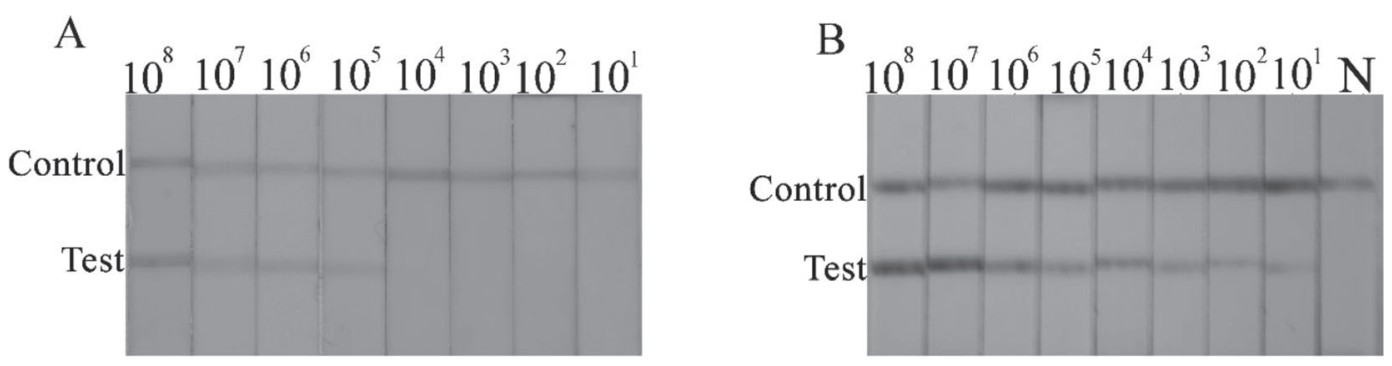

Figure 4. The sensitivity of PCR lateral flow (LF; A) and recombinase polymerase amplification (RPA)-LF (B) assays using DNA extracted from $1.05 \times 10^{1}$ to $1.05 \times 10^{8} \mathrm{cfu} / \mathrm{mL}$ in pure culture by boiling in sterile water. $\mathrm{N}$ represents negative control. 


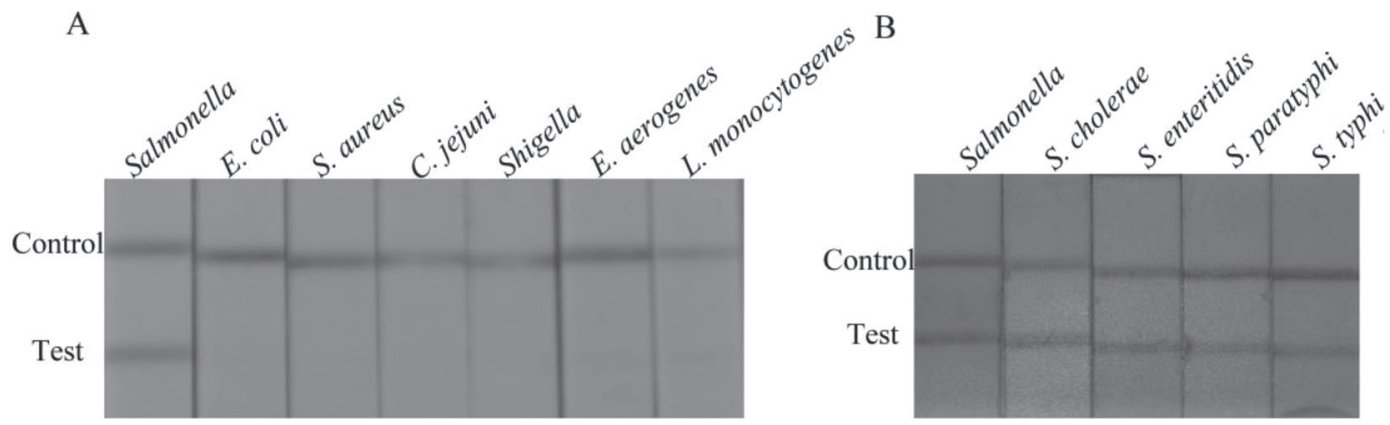

Figure 5. Molecular specificity of the recombinase polymerase amplification (RPA) lateral-flow (LF) assay using 6 non-Salmonella bacteria (A) and 5 Salmonella bacteria (B). E. coli = Escherichia coli; S. aureus = Staphylococcus aureus; . jejuni = Campylobacter jejuni; E. aerogenes $=$ Enterobacter aerogenes; L. monocytogenes $=$ Listeria monocytogenes.

chicken breast, and egg, respectively. In addition, egg containing $1.05 \times 10^{\circ} \mathrm{cfu} / \mathrm{g}$ Salmonella produced a positive result after enrichment for $4 \mathrm{~h}$.

\section{DISCUSSION}

Currently, the high prevalence of Salmonella poses a great risk to public health (Abirami et al., 2016). Rapid detection methods that can shorten the detection time for Salmonella and limit the dissemination of Salmonella along the food chain are needed (Abirami et al., 2016). However, current detection methods require expensive instruments or inconvenient, time-consuming procedures that severely limit their suitability for point-of-use detection (Rohde et al., 2016). Recombinase polymerase amplification is a recently described isothermal amplification technique that can amplify target DNA to detectable levels in less time and at a lower constant temperature than other isothermal amplification procedures, such as helicase-dependent amplification (Ramalingam et al., 2009), loop-mediated isothermal amplification (Cornelissen et al., 2016), and rolling circle amplification (Zhu et al., 2014). In addition, RPA is tolerant to impure samples (Krõlov et
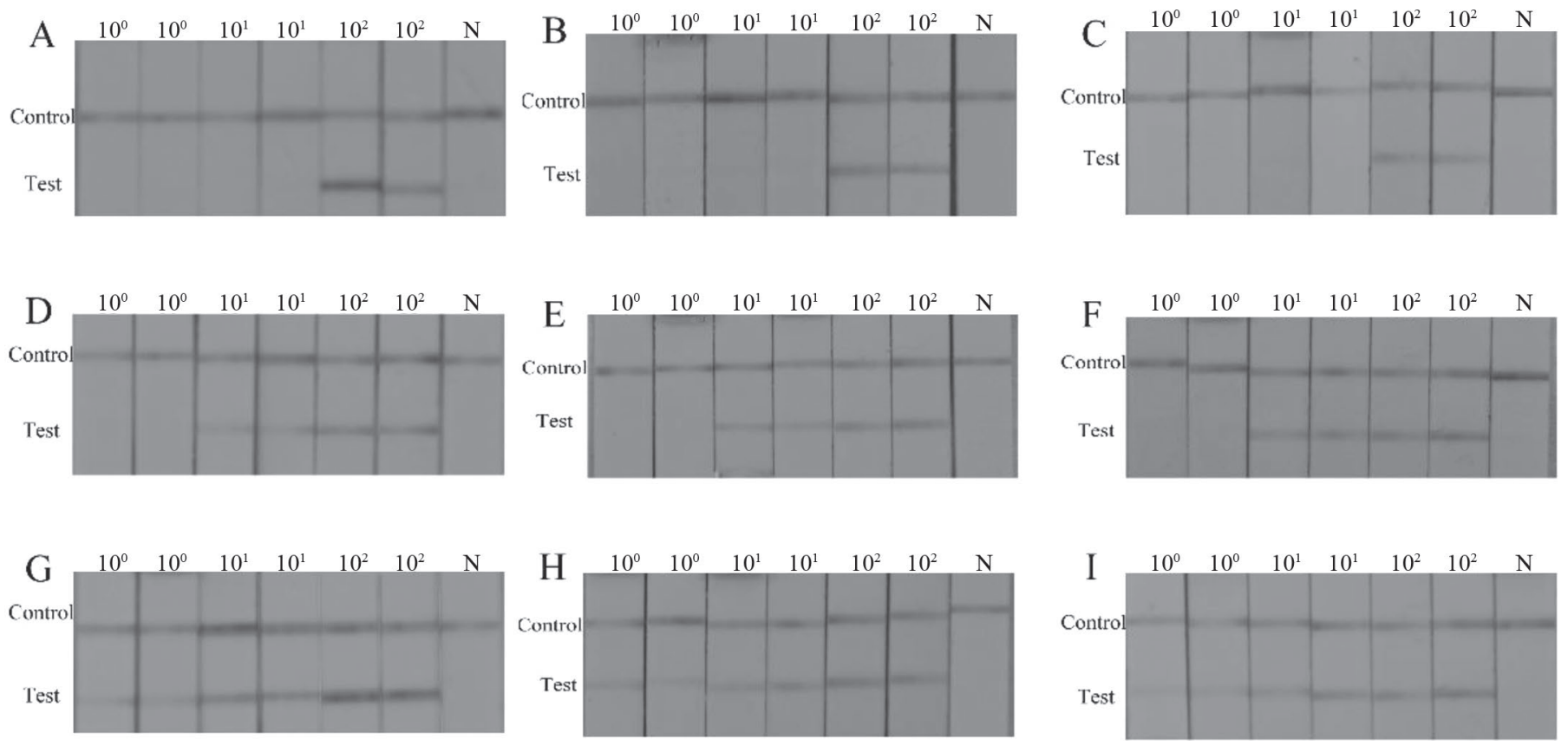

Figure 6. Typical photographs of the analytical performance of recombinase polymerase amplification (RPA) lateral flow (LF) in milk (A, D, G), chicken breast (B, E, H), and egg (C, F, I) after inoculation with $10^{0}, 10^{1}$, or $10^{2} \mathrm{cfu} / \mathrm{mL}$ or cfu/g Salmonella after different enrichment times. (A), (B), and (C): RPA-LF result of incubation at $37^{\circ} \mathrm{C}$ for $0 \mathrm{~h}$ after inoculation; (D), (E), (F): RPA-LF result of incubation at $37^{\circ} \mathrm{C}$ for 1 $\mathrm{h}$ after inoculation; $(\mathrm{G})$ and $(\mathrm{H})$ : RPA-LF result of incubation at $37^{\circ} \mathrm{C}$ for $2 \mathrm{~h}$ after inoculation; and (I): RPA-LF result obtained from egg after incubation for $4 \mathrm{~h}$. $\mathrm{N}$ represents the negative control. 
al., 2014). Thus, DNA purification from samples is not required, which eliminates the cost and time required for DNA extraction. These advantages make RPA particularly suitable for use in remote regions (Supplemental Table S1; https://doi.org/10.3168/jds.2017-12566). Currently, the cost of the RPA-LF assay is higher than that of PCR-LF; however, this cost is expected to decrease with increased development and usage (Silva et al., 2015). The LF strips are promising tools that translate isothermal amplification into a visual test and eliminate the need for trained personnel, expensive materials, and other external apparatus. An assay combining RPA and LF strips would have many advantages, such as simple operation, fast detection, rapid reaction, and low energy consumption (Kolm et al., 2015; Rivas et al., 2015). The LF strips were stable for at least 6 mo at room temperature. As shown in Supplemental Figure S2 (https://doi.org/10.3168/jds.2017-12566), the brightness of the bands did not significantly differ between newly (LF1) and previously (LF2) prepared LF strips. Thus, the RPA-LF assay is suitable for the point-of-use diagnosis of Salmonella infection.

The RPA-LF assay is based on the sandwich-type hybridization reaction, which relies on the antigenantibody reaction. Under suitable conditions, RPA produces amplification products concurrently labeled with digoxin and biotin. The streptavidin on the test line captures biotin, attached on one end of the RPA products, and digoxin, attached on the other end, is captured by anti-digoxin antibody coated on AuNP. The accumulation of AuNP on the test line produces a visual band. The assay was capable of detecting as few as $1.05 \times 10^{1}$ cfu and had a detection limit of 20 fg of DNA per test. This detection limit is in the same range as those of other nucleic acid amplification-based techniques (Chen et al., 2015, 2016; Cornelissen et al., 2016). Thus, the RPA-LF assay is much more sensitive than culture-based methods, and the PCR-LF assay has a detection limit 4 orders of magnitude higher than that of the RPA-LF assay. The culture enrichment of samples before target detection is necessary because the contamination levels are often below the detection limit. Food samples were artificially inoculated with Salmonella (spiked level: $1.05 \times 10^{0}$ to $1.05 \times 10^{2}$ $\mathrm{cfu} / \mathrm{g}$ or $1.05 \times 10^{0}$ to $\left.1.05 \times 10^{2} \mathrm{cfu} / \mathrm{mL}\right)$, and the RPA-LF assay produced a positive result at $0 \mathrm{~h}$ for milk and chicken breast containing an initial bacteria concentration of $1.05 \times 10^{2} \mathrm{cfu} / \mathrm{mL}$ or $1.05 \times 10^{2} \mathrm{cfu} / \mathrm{g}$. Additionally, following a 1-h incubation, the RPA-LF assay allowed detection of an initial bacteria concentration of $1.05 \times 10^{2} \mathrm{cfu} / \mathrm{g}$ in egg. The chicken breast and milk matrices did not affect the analytical sensitivity of RPA, and the limit of detection was in the same range as that for pure bacterial culture. However, our study revealed that the sensitivity of the RPA-LF assay was reduced in eggs relative to milk or chicken breast. According to our study, the selenite cystine broth (Beijing Land Bridge Technology Co., Ltd.), which was used to selectively enrich Salmonella, significantly affected the RPA, resulting in a large number of primer dimers and leading to false-positive results on the LF strips. Therefore, in the food sample detection, LB broth was used for enrichment culturing rather than selenite cystine broth.

Additional benefits of the RPA-LF assay are its short incubation time, avoidance of DNA purification steps, and low, single incubation temperature $\left(35-45^{\circ} \mathrm{C}\right)$, which can be slightly higher than the surrounding temperature (Lillis et al., 2014). Thus, a water bath kettle is sufficient to achieve accurate detection (Crannell et al., 2014). This assay does not require the purification of DNA from samples. Therefore, heating the sample at $95^{\circ} \mathrm{C}$ for 10 min was sufficient to release the target DNA and certify the presence of the target pathogen. The omission of the DNA purification step before RPA amplification made the assay less time consuming and less expensive. The RPA-LF assay produces a visual band on the test line, which can be observed without magnification by untrained personnel in less than 30 min; this time includes time required for preparing the genomic DNA, and performing the RPA reaction and strip detection. Furthermore, the RPA reaction and LF test do not require any expensive equipment, which is important for pathogen detection in remote areas. The RPA reaction scheme, similar to the PCR reaction, uses only 2 primers, and it can be easily adapted to detect other pathogens. It also has the potential for use in multiplex reactions.

The RPA-LF assay is an attractive detection method that is suitable for point-of-use diagnosis and the mass monitoring of food. However, before the RPA assay can be widely applied, improvements are required. One drawback of the RPA-LF assay is that false-positive results can occur because of the primer dimers that simultaneously carry the biotin and digoxin. As in the PCR reaction, they are formed with similar efficiencies as the target sequence (Kolm et al., 2015). This problem can be solved by selecting the most suitable primers and heating slightly below the Tm of the RPA product. The Tm of the product is the temperature at which half of the complementary base pairs in the product become melted. Thus, heating below the Tm can dissolve the primer dimer without affecting the product. As shown in Supplemental Figure S3 (https:/ / doi.org/10.3168/jds.2017-12566), false positives can be eliminated by optimizing the heating temperature and heating time. After heating at $82^{\circ} \mathrm{C}$ for $5 \mathrm{~min}$, no primer dimers carrying both biotin and digoxin were detected; 
under these conditions, the detection of Salmonella on the LF strip is not affected by primer dimers. Another drawback is that false-positive results can be caused by low levels of contamination with previously amplified nucleic acid fragments. The operator should ensure that the cap of the RPA amplification tube is not opened in the sample-handling area to prevent the formation of aerosol pollution. Therefore, the enrichment of bacteria in culture and the RPA reaction should be performed with care to avoid accidental laboratory contamination (Binet et al., 2014).

\section{CONCLUSIONS}

This study combined the RPA reaction with a nucleic acid LF immunostrip for the rapid detection of Salmonella bacteria. This immunostrip detection method, which uses inexpensive capillary action based on an overlapping paper membrane system, offers rapid visual detection results. The RPA-LF assay is highly specific and has a detection limit of $1.05 \times 10^{1}$ cfu in pure culture or $20 \mathrm{fg}$ of DNA within 30 min using simple water bath equipment. Compared with conventional PCR and other isothermal amplification methods, the RPA reaction is much simpler, requires a shorter incubation time, and avoids the need for specialized personnel or expensive instruments. This sensor can be used to rapidly test food samples, such as samples of chicken breasts, eggs, and milk, without any sample pretreatment or technical expertise. Additionally, we were able to eliminate false positives caused by primer dimer generation during amplification by heating at $82^{\circ} \mathrm{C}$ for $5 \mathrm{~min}$. The combination of RPA and LF is thus a promising on-site detection technology to monitor Salmonella infection.

\section{ACKNOWLEDGMENTS}

This study received financial support from a project of the Ministry of Science and Technology of the People's Republic of China (project no. 2014BAD04B03), International Science and Technology Cooperation Program of China (project no. 2014DFR30350), and the Excellent Doctoral Fund Project of Tianjin University of Science and Technology (no. 2016003).

\section{REFERENCES}

Abirami, N., H. Nidaullah, L. O. Chuah, A. K. Shamila-Syuhada, S. R. Chandraprasad, N. Huda, H. Hasmaizal, and G. Rusul. 2016. Evaluation of commercial loop-mediated isothermal amplification based kit and ready-to-use plating system for detection of Salmonella in naturally contaminated poultry and their processing environment. Food Contr. 70:74-78. https://doi.org/10.1016/j. foodcont.2016.05.035.
Abouzeed, Y. M., H. Hariharan, C. Poppe, and F. S. B. Kibenge 2000. Characterization of Salmonella isolates from beef cattle, broiler chickens and human sources on Prince Edward Island. Comp. Immunol. Microbiol. Infect. Dis. 23:253-266. https://doi. org/10.1016/s0147-9571(99)00079-x.

Binet, R., D. M. Deer, and S. J. Uhlfelder. 2014. Rapid detection of Shigella and enteroinvasive Escherichia coli in produce enrichments by a conventional multiplex PCR assay. Food Microbiol. 40:48-54. https://doi.org/10.1016/j.fm.2013.12.001.

Centers for Disease Control and Prevention (CDC). 2014. Estimates of food-borne illness in the United States. Accessed Jan. 22, 2016. http://www.cdc.gov/foodborneburden/.

Chao, C. C., T. Belinskaya, Z. W. Zhang, and W. M. Ching. 2015. Development of recombinase polymerase amplification assays for detection of orientia tsutsugamushi or rickettsia typhi. PLoS Negl. Trop. Dis. 9:e0003884. https://doi.org/10.1371/journal. pntd.0003884.

Chen, X., X. Wu, M. Gan, F. Xu, L. H. He, D. Yang, H. Y. Xu, N. P. Shah, and H. Wei. 2015. Rapid detection of Staphylococcus aureus in dairy and meat foods by combination of capture with silicacoated magnetic nanoparticles and thermophilic helicase-dependent isothermal amplification. J. Dairy Sci. 98:1563-1570. https:// doi.org/10.3168/jds.2014-8828.

Chen, Y. T., N. Cheng, Y. C. Xu, K. L. Huang, Y. B. Luo, and W. T. Xu. 2016. Point-of-care and visual detection of P. aeruginosa and its toxin genes by multiple LAMP and lateral flow nucleic acid biosensor. Biosens. Bioelectron. 81:317-323. https://doi. org/10.1016/j.bios.2016.03.006.

Cordray, M. S., and R. R. Richards-Kortum. 2015. A paper and plastic device for the combined isothermal amplification and lateral flow detection of Plasmodium DNA. Malar. J. 14:472. https://doi. org/10.1186/s12936-015-0995-6.

Cornelissen, J., A. De Greeff, A. E. Heuvelink, M. Swarts, H. E. Smith, F. J. Van der Wal, and Health4Food-Dutch Mastitis Diagnostics Consortium. 2016. Rapid detection of Streptococcus uberis in raw milk by loop-mediated isothermal amplification. J. Dairy Sci. 99:4270-4281. https://doi.org/10.3168/jds.2015-10683.

Crannell, Z. A., B. Rohrman, and R. Richards-Kortum. 2014. Equipment-free incubation of recombinase polymerase amplification reactions using body heat. PLoS One 9:e112146. https://doi org/10.1371/journal.pone.0112146.

Dzantiev, B. B., N. A. Byzova, A. E. Urusov, and A. V. Zherdev. 2014 Immunochromatographic methods in food analysis. Trends Analyt. Chem. 55:81-93. https://doi.org/10.1016/j.trac.2013.11.007.

Gill, P., and A. Ghaemi. 2008. Nucleic acid isothermal amplification technologies-A review. Nucleosides Nucleotides Nucleic Acids 27:224-243. https://doi.org/10.1080/15257770701845204.

Hellyer, T. J., and J. G. Nadeau. 2004. Strand displacement amplification: A versatile tool for molecular diagnostics. Expert Rev. Mol. Diagn. 4:251-261. https://doi.org/10.1586/14737159.4.2.251.

Hwang, J., S. Lee, and J. Choo. 2016. Application of a SERS-based lateral flow immunoassay strip for the rapid and sensitive detection of staphylococcal enterotoxin B. Nanoscale 8:11418-11425. https://doi.org/10.1039/c5nr07243c.

Khueankhancharoen, J., A. Thipayarat, and J. Saranak. 2016. Optimized microscale detection of amino acid decarboxylase for rapid screening of Salmonella in the selective enrichment step. Food Contr. 69:352-367. https://doi.org/10.1016/j.foodcont.2016.05.002.

Kim, J., and C. J. Easley. 2011. Isothermal DNA amplification in bioanalysis: Strategies and applications. Bioanalysis 3:227-239. https://doi.org/10.4155/bio.10.172.

Kolm, C., R. L. Mach, R. Krska, and K. Brunner. 2015. A rapid DNA lateral flow test for the detection of transgenic maize by isothermal amplification of the 35S promoter. Anal. Methods 7:129-134. https://doi.org/10.1039/c4ay01997k.

Krõlov,, K., J. Frolova, O. Tudoran, J. Suhorutsenko, T. Lehto, H. Sibul, I. Mager, M. Laanpere, I. Tulp, and O. Langell. 2014. Sensitive and rapid detection of Chlamydia trachomatis by recombinase polymerase amplification directly from urine samples. J. Mol. Diagn. 16:127-135. https://doi.org/10.1016/j.jmoldx.2013.08.003. 
Kutay, H. C., E. Dumen, O. Keser, A. S. Bilgin, S. Ergin, and N. Kocabagli. 2016. Prevalence and antimicrobial susceptibility of Salmonella in rendered animal products used in poultry feed in turkey. Kafkas Univ. Vet. Fak. Derg. 22:909-916. https://doi. org/10.9775/kvfd.2016.15657.

Li, S. K., A. Y. Chen, Y. Q. Chai, R. Yuan, and Y. Zhuo. 2016. Electrochemiluminescence aptasensor based on cascading amplification of nicking endonuclease-assisted target recycling and rolling circle amplifications for mucin 1 detection. Electrochim. Acta 212:767774. https://doi.org/10.1016/j.electacta.2016.07.074.

Lillis, L., D. Lehman, M. C. Singhal, J. Cantera, J. Singleton, P. Labarre, A. Toyama, O. Piepenburg, M. Parker, R. Wood, J. Overbaugh, and D. S. Boyle. 2014. Non-instrumented incubation of a recombinase polymerase amplification assay for the rapid and sensitive detection of proviral HIV-1 DNA. PLoS One 9:e108189 https://doi.org/10.1371/journal.pone.0108189.

Liu, Q., J. Nam, S. Kim, C. T. Lim, M. K. Park, and Y. Shin. 2016. Two-stage sample-to-answer system based on nucleic acid amplification approach for detection of malaria parasites. Biosens. Bioelectron. 82:1-8. https://doi.org/10.1016/j.bios.2016.03.050.

Lutz, S., P. Weber, M. Focke, B. Faltin, J. Hoffmann, C. Muller, D. Mark, G. Roth, P. Munday, N. Armes, O. Piepenburg, R. Zengerle, and F. von Stetten. 2010. Microfluidic lab-on-a-foil for nucleic acid analysis based on isothermal recombinase polymerase amplification (RPA). Lab Chip 10:887-893. https://doi.org/10.1039/ b921140c.

Millan-Sango, D., E. Garroni, C. Farrugia, J. F. M. Van Impe, and V. P. Valdramidis. 2016. Determination of the efficacy of ultrasound combined with essential oils on the decontamination of Salmonella inoculated lettuce leaves. Lebensm. Wiss. Technol. 73:80-87. https://doi.org/10.1016/j.lwt.2016.05.039.

People's Republic of China. 2010. GB/T4789.4-2010. National food safety standard of China, Food microbiological examination: Salmonella. Accessed Jul. 6, 2017. http://down.foodmate.net/ standard/sort/3/50369.html.

Piepenburg, O., C. H. Williams, D. L. Stemple, and N. A. Armes. 2006. DNA detection using recombination proteins. PLoS Biol. 4:e204. https://doi.org/10.1371/journal.pbio.0040204.
Ramalingam, N., T. C. San, T. J. Kai, M. Y. M. Mak, and H. Q. Gong. 2009. Microfluidic devices harboring unsealed reactors for real-time isothermal helicase-dependent amplification. Microfluid. Nanofluidics 7:325-336. https://doi.org/10.1007/s10404-008-03781.

Rivas, L., A. de la Escosura-Muniz, L. Serrano, L. Altet, O. Francino, A. Sanchez, and A. Merkoci. 2015. Triple lines gold nanoparticlebased lateral flow assay for enhanced and simultaneous detection of Leishmania DNA and endogenous control. Nano Res. 8:37043714. https://doi.org/10.1007/s12274-015-0870-3.

Rohde, A., J. A. Hammerl, and S. Al Dahouk. 2016. Detection of foodborne bacterial zoonoses by fluorescence in situ hybridization. Food Contr. 69:297-305. https://doi.org/10.1016/j. foodcont.2016.05.008.

Silva, G., M. Bömer, C. Nkere, P. L. Kumar, and S. E. Seal. 2015. Rapid and specific detection of Yam mosaic virus by reverse-transcription recombinase polymerase amplification. J. Virol. Methods 222:138-144. https://doi.org/10.1016/j.jviromet.2015.06.011.

Yang, Q. R., K. J. Domesle, F. Wang, and B. L. Ge. 2016. Rapid detection of Salmonella in food and feed by coupling loop-mediated isothermal amplification with bioluminescent assay in real-time. BMC Microbiol. 16:112. https://doi.org/10.1186/s12866-016-07307.

Zhao, X. J., L. R. Hilliard, S. J. Mechery, Y. P. Wang, R. P. Bagwe, S. G. Jin, and W. H. Tan. 2004. A rapid bioassay for single bacterial cell quantitation using bioconjugated nanoparticles. Proc. Natl. Acad. Sci. USA 101:15027-15032. https://doi.org/10.1073/ pnas.0404806101.

Zhu, D., Y. R. Yan, P. H. Lei, B. Shen, W. Cheng, H. X. Ju, and S. J. Ding. 2014. A novel electrochemical sensing strategy for rapid and ultrasensitive detection of Salmonella by rolling circle amplification and DNA-AuNP probe. Anal. Chim. Acta 846:44-50. https:// doi.org/10.1016/j.aca.2014.07.024. 